\title{
PEDAGOGÍA DE LO SENSIBLE: SUBJETIVIDADES ENCARNADAS EN LA ESCUELA
}

\section{Resumen}

Este trabajo propone al lector transitar por lo que hemos convenido en denominar como pedagogía sensible. La pedagogía sensible se posiciona en contra de las miradas negativas al cuerpo en los dispositivos educativos. Más allá de concepción de la educación como la transmisión de conocimientos a través de procesos intelectuales, proponemos una exploración por los sentidos corporales y sus posibilidades pedagógicas.

Palabras clave: Pedagogía de lo sensible, cuerpo, carne, subjetividad, pedagogía anestesiante

\section{TEACHING OF THE SENSITIVE. EMBODIMENTS SUBJECTIVITIES AT SCHOOL}

\begin{abstract}
This paper offers the reader move so we have agreed to call as sensitive pedagogy. Sensitive pedagogy is positioned against the body negative views on educational devices. Beyond the concept of education as transmission of knowledge through intellectual processes, we propose an exploration through the bodily senses and their pedagogical possibilities.
\end{abstract}

Keywords: Senses Pedagogy, body, flesh, subjectivity, anesthetizing pedagogy

\footnotetext{
${ }^{1}$ Jordi Planella Ribera, Doctor en Pedagogía por la Universidad de Barcelona, Catedrático de Teoría e Historia de la Educación en al Universitat Oberta de Catalunya (UOC, Barcelona). E-mail: jplanella@uoc.edu
} 


\title{
PEDAGOGIA DO SENSÍVEL. SUBJETIVIDADES ENCARNADAS NA ESCOLA.
}

\begin{abstract}
Resumo
Este trabalho propõe o leitor a viajar assim que nós concordamos em chamar a pedagogia sensível. Pedagogia sensível é posicionada contra as visões negativas do corpo em dispositivos educacionais. Além da concepção da educação como transmissâo de conhecimento a través de processos intelectuais, propomos uma exploração dos sentidos do corpo e suas possibilidades pedagógicas.
\end{abstract}

Palavras-chave: Pedagogia do sensível, corpo, carne, subjetividade, pedagogía anestesiante

\section{INTRODUCCIÓN: DE CUERPOS Y EDUCACIONES}

\begin{abstract}
Yo soñaba con escuelas donde los profesores fueran guías y consejeros, no supervisores de tareas. Frank McCourt (2008). El profesor. Madrid: Maeva, p. 36.

Existe un único tiempo en el universo, que es el Cuerpo del Hombre. Nada hay más sagrado que esta forma elevada. Inclinarse ante el hombre es hacer una verdadera reverencia a esa Revelación de la Carne. Tocamos en cielo cuando ponemos nuestras manos sobre un cuerpo humano. Novalis (1772).
\end{abstract}

La cuestión que planteo en el presente texto lleva años ocupándome y preocupándome y que a falta de otras denominaciones (así como de una cierta evolución en las nomenclaturas y las formas de llamarla) me gusta definirla como Pedagogía Sensible o Pedagogía de lo Sensible. A muchas personas (profesionales, profesores, padres, políticos, técnicos, etc.) les puede parecer un tema efímero, poco interesante, periférico, excesivamente teórico. Voy a intentar exponer justo lo contrario para hacer ver su centralidad en las praxis y reflexiones pedagógicas. Si, lo que voy a mostrar se sitúa en el orden de la reflexión, del Pensamiento Pedagógico (que puede tomar forma y nombre en otras disciplinas pero que al fin y al cabo hablan y se refieren a lo mismo: Filosofía de la Educación, Antropología Pedagógica, Teoría de la Educación o Pedagogía Sistemática). Trabajo desde la Producción de Saberes más allá de las posiciones epistemológicas centradas en las miradas excesivamente "cientifistas", o científicas, o 
cuantitativas o incluso excesivamente metodológicas a la educación. Podríamos hablar únicamente de las operaciones de leer, pensar y escribir!!! Digamos que me interesa mucho más el concepto de hermenéutica que el de estadística. En mi universidad ocupo la Cátedra de Teoría e Historia de la Educación y es desde esta plataforma y del grupo de investigación que dirijo, Laboratorio de Educación Social, que realizo mis investigaciones.

La educación sigue estando, de manera constante, en el centro de los huracanes críticos, en la mirada de los políticos (y de las políticas sociales, educativas y económicas que estos impulsan - o bien que no impulsan -, o que impulsan de determinadas formas que a las voces críticas no nos acaban de gustar), en las reflexiones y preocupaciones de determinada parte de la sociedad. Pero creo que a pesar de ello es pertinente que nos preguntemos si: ¿Esas miradas y esas reflexiones sirven para mejorar la educación? ¿Sirven para recuperar algunas experiencias que antaño permitieron otras formas de concretar el ejercicio pedagógico? ¿Debemos partir siempre de cero cuando proponemos proyectos educativos o seremos capaces de sacar el polvo a teorías, pedagogos y proyectos que antes que nosotros recorrieron esos senderos?

Se trataría de hacer una verdadera Arqueología de la Escuela en el sentido genuinamente foucaultiano, ya que nos dirá que "la genealogía debe mostrar el cuerpo impregnado de historia, y la historia arruinando el cuerpo" (FOUCAULT, 1969). Lo que propongo a lo largo del texto, es adentrarnos en las formas, pasadas y actuales, que han permitido la posibilidad y el desarrollo de una pedagogía sensible, una pedagogía que ha hecho posible una educación corporal más allá de los cánones "platónicos" o "cartesianos”, (excesivamente centrados en la recepción de saberes a través del intelecto). Una Pedagogía que no tome posiciones aferradas en posturas y miradas corpofóbicas.

A pesar que en las últimas décadas hemos asistido a significativos cambios en las formas de entender y ejercer la educación (aunque casi siempre bajo las categorías de aparente cambio como son las nuevas tecnologías o la idea misma de competencias), en la actualidad nos seguimos encontrando con flagrantes contradicciones que nos obligan a pensar, a seguir buscando otras vías para ejercer las profesiones pedagógicas. De hecho (y esto es una cuestión fundamental) la Pedagogía está llamada a seguir - siempre - buscando nuevas vías, nuevas formas de pensar y de ejercer el bello oficio de la educación. A no quedarse anquilosada en formas estáticas de pensar, a discutir y pensar la relación entre los sujetos de la educación, las praxis pedagógicas y la consecución del estatus de ciudadanía. Tal y como nos propone 
Catherine Walsh "Las luchas sociales también son escenarios pedagógicos donde los participantes ejercen sus pedagogías de aprendizaje, desaprendizaje, reaprendizaje, reflexión y acción (...). Las pedagogías, en este sentido, son las prácticas, estrategias, metodologías que se entretejen con y se construyen tanto en la resistencia y la oposición, como en la insurgencia, el cimarronaje, la afirmación, la re-existencia y la re-humanización” (WALSH, 2013: 29).

Desde hace unos años me vengo ocupando y preocupando sobre temas que conciernen al cuerpo y la educación (PLANELLA 2006, 2015). Muchas veces se visualiza y concibe como un tema periférico y menor. Para mi es un tema central y de una gran relevancia en el campo ped. No hablo de la "educación del cuerpo" si no del cuerpo y la educación. Me gusta, de forma consciente, romper esa clásica perspectiva que entendía - y sigue entendiendo todavía - que el cuerpo debe ser educado (y por educación corporal se entieden ciertas formas de "domesticación" de dichos cuerpos), que debe actuarse sobre él. La educación del cuerpo va mucho más allá de esta visión restringida que lo asimila a algo anatómico, biomecánico o fisiológico. Voy a intentar mostrar como más allá de esta idea (educar al cuerpo), el cuerpo es en realidad un elemento central de las praxis educativas, hasta el punto que podemos atrevernos a afirmar que "sin cuerpo no hay educación". En este sentido, no se trata de volver a ofrecer formulas cerradas que nos den indicaciones de qué hacer con el cuerpo. Más bien se trata de abrir, puertas y ventanas, a las posibilidades de:

- hacer con el cuerpo;

- hacer desde el cuerpo;

- hacer al cuerpo;

- aprender el cuerpo;

- aprehender el cuerpo;

- aprender desde el cuerpo;

- aprender con el cuerpo;

- etc.

Y no la clásica perspectiva que hablaba de iiaprender a pesar del cuerpo!!

Dichas aperturas en la mirada al cuerpo se abren a un sinfín de posibilidades pedagógicas que bien merecen ser pensadas y aprovechadas al servicio de una educación que no niegue ni reniegue de la dimensión corporal e integral de los sujetos. 
De forma habitual es la inercia - una determinada manera de actuar - la que nos conduce a realizar ciertos ejercicios de repetición y que nos lleva a situaciones de "permanencia". En cierto modo es lo que viene sucediendo en una parte de la actual praxis educativa. Una simple mirada a esas prácticas educativas nos permite darnos cuenta que se encuentran alineadas con las pedagogías que podemos denominar de "corte cartesiano". Son pedagogías que niegan el cuerpo, que les molesta el cuerpo, que prefieren "sujetos sin cuerpo". De lo que se trata es en realidad de discutir sobre las posibilidades de una mirada sensible, de una pedagogía sensible que se preocupe por esas otras dimensiones del sujeto que muy a menudo quedan ofuscadas por las técnicas de parametrización de la diferencia, por la clasificación (ordenar), por la cuantificación, por la necesidad (injusta) de tener controlado a todo aquel que vive en los y a lo que pueda representar ello de peligroso para nuestras vidas (unas vidas consideradas dentro de los parámetros de la normalidad).

Se trata de pensar una pedagogía sensible frente a una pedagogía anestesiada o anestesiante. Y al pensar en ello me viene a la mente la expresión de Spinoza, cuando nos dice que "nadie sabe lo que puede un cuerpo" (BENITO, 2015). Y nos sigue diciendo: "Y el hecho es que nadie, hasta ahora, ha determinado lo que puede un cuerpo, es decir, a nadie ha enseñado la experiencia, hasta ahora, lo que puede hacer el cuerpo". También me parece relevante lo que plantea Edmund Husserl en relación al cuerpo cuando en su libro "Ideas II" expone temas vinculados a la experiencia corporal, una experiencia del orden sensorio-motriz que atraviesa mi vida. Termina por decirnos que "yo con el cuerpo puedo realizar muchos actos, muchas cosas", (se trata de una conexión radical con la idea de Spinoza). Experimento mi cuerpo por dentro, a diferencia de algunos objectos de les cuales puedo llegar a tener cierta experiencia de orden visual. En "Ideas II", Husserl describe el modo de constitución del cuerpo propio integrando los problemas psicofisológicos en la definición misma de hombre, de ser humano (ANDRIEU, 1993: 247). Desde esta mirada podemos situar y entender al cuerpo como la existencial del Yo y de la Cultura. Husserl nos llevará a la diferencia (importante y radical) entre Körper (cuerpo físico ) y Leib (cuerpo vivido o también cuerpo simbólico).

Es justamente en la apertura que esa duda nos ofrece (el hecho de desconocer las potencialidades del cuerpo del sujeto), que aparece, crece y toma fuerza la idea de una resistencia por parte del sujeto, de un "no dejarse anestesiar" por el sistema. Para el filósofo español, José María Esquirol, "resistir no es propio solo de anacoretas y ermitaños. Existir es, en parte resistir. Entonces la resistencia expresa no un mero hecho circunstancial, sino una 
manera de ser, un movimiento de la existencia humana" (ESQUIROL, 2015, p. 9). Porqué en el dejarse anestesiar, en el no resistir, tiene lugar la caducidad del sujeto, la pérdida de reacción, el ocultamiento de sus posibles maniobras o el pasar a ser algo más que alguien (objeto versus sujeto). Anestesia es una palabra de origen griego que significa, justamente, "ausencia de sensaciones". El estado de ausencia de dolor, por ejemplo, para las intervenciones quirúrgicas, contrasta con su sentido en el campo educativo. Es así que podríamos hablar de:

$$
\begin{aligned}
& \text {-pedagogía Anestesiada } \\
& \text {-pedagogía Anestesiante. }
\end{aligned}
$$

Una pedagogía anestesiada toma la forma verbal del pasado y se presenta como algo ya cerrado y concluido; la pedagogía anestesiante toma la formal verbal -activa- de la potencia, del potencial futuro. La idea de la pedagogía anestesiante me apareció muy clara cuando en agosto pasado visité el Museo de Historia de la Medicina de Rio Grande do Sul (MUHM, Porto Alegre). Allí había una sección amplia dedicada a la anestesia. Ya sabemos que la finalidad de la anestesia es la paralización de determinadas partes del cuerpo humano para realizar algún tipo de operación en ellas o con ellas. No despertar al sujeto (con sus pasiones, saberes, placeres, encarnaciones) sino mantenerlo dormido (si puede ser bien dormido), pasivo corporalmente. He aquí la finalidad de determinadas Pedagogías. Una finalidad que contrastaría con una idea de la escuela como "una vivencia de seres humanos en relación con la búsqueda conjunta de saberes para la mejora de la sociedad en la que convivimos" (ROMERO, p. 12). Pasa a ser, entonces, un cuerpo tendido en una camilla, en un quirófano, o bien sentado pasivamente en un pupitre de nuestras escuelas, sin moverse, atento y sin molestar. De ese sujeto de la educación se espera -sobretodo- que no se mueva, que esté pasivo (¿no es ese el significado de paciente en el campo médico?. Un significado que se postula contrario a lo que nos decía Lacan: "yo hablo con mi cuerpo, y eso sin saberlo. Digo pues siempre más de lo que sé" (citado en UBIETO, 2014, p. 3). Y eso, a la educación le sigue costando de entender y aceptar. Para muchas pedagogías los cuerpos no hablan, son silencio y no gritos desgarrados. Para Ubieto se trata que:

Una manera contemporánea de responder con el cuerpo a la presencia del "otro", sea bajo forma verborreicas del niño que no hace sino interrumpir al profesor/adulto, o la desatenta de ignorarlo. En los dos casos podemos ver una modalidad del vínculo que 
nos habla de una dificultad creciente de la palabra para regular lo que se agita en el cuerpo (UBIETO, 2014, p. 13).

A veces pienso que se produce un proceso de ruptura pedagógica que en realidad es así de simple: hasta una determinada edad (que puede variar enormemente en cada contexto escolar y social) el cuerpo es el elemento central del ejercicio de la educación. Aprendemos desde el cuerpo, a pesar de que seguimos aprendiendo muchas cosas sobre el cuerpo. Aprendemos con el tacto, con los sabores, con los olores, a través del despliegue de múltiples sensibilidades. Es algo que fácilmente podemos conectar con la idea primaria del placer o con el deseo, ya que se trata de sensaciones agradables que vinculan, en cierta forma, lo que aprendemos con nuestra sensibilidad. Me gusta llamar a este tipo de pedagogía (que bebe de fuentes pedagógicas como el naturalismo de Rousseau o los proyectos al aire libre de la Escuela Nueva), Pedagogía Sensible. Sensible porqué permite (y obliga) a poner en circulación los sentidos de los educandos, y sensible también porqué demuestra que es algo contrario a una Pedagogía Anestesiada o Anestesiante. Podemos ver en este tipo de pedagogía una pedagogía que se abre a las posibilidades del cuerpo por que a la vez busca despertar al educando, no dejarlo dormido, darle la palabra y, en cierta forma, permitirle circular. La sensibilidad se posiciona contraria a la anestesia pero también a la "insipidez".

Si abro un diccionario de la lengua general cualquiera, la perspectiva lexicográfica que nos ofrece el término sensible hace referencia a alguien que "es capaz de percibir sensaciones ... Susceptible de percibir un cambio... Que es perceptible por los sentidos". Y si busco sus sinónimos encuentro palabras como: "impresionable, delicado, emotivo, afectivo, sentimental, compasivo, tierno, sensitivo, blando, perceptible". Se trata, se mire por donde se mire, de una vinculación con el cuerpo, de saborear las sensaciones e implicaciones corporales. De entender la educación, en palabras de Assman, desde la idea central que "procesos de vida y procesos de aprendizaje son la misma cosa" (ASSMANN, 2002, p. 49). Su objetivo es despertar todos los sentidos de los niños, ponerlos en movimiento y provocar que exista cierta actividad de orden corporal. Y ello termina convirtiéndose en algo contradictorio porqué una parte importante de los rituales que se llevan a cabo en las instituciones educativas tienen bastante que ver con los usos del cuerpo y con el dominio de determinadas técnicas corporales. Desde el uso de instrumentos para el aprendizaje (aprender a utilizar un lápiz para escribir y de esa forma aprende a "dominar el trazo, o aprender a utilizar el ratón y el teclado de una computadora para teclear textos que deberán ser leídos y evaluados por otros) hasta el aprendizaje de técnicas que 
sirven para ejecutar el borramiento de los signos del periodo en las chicas adolescentes (disimular, esconder y eliminar manchas, formas y olores) la pedagogía no puede escapar al cuerpo.

A veces vemos al cuerpo de los estudiantes como un especie de "fierecilla salvaje" que requiere ser domada para que puedan aprender lo que nosotros, como docentes, hemos decidido que aprendan. Alguien podrá afirmar que no hay procesos de aprendizaje sin domesticaciones previas o paralelas. Craso error, pero ya sabemos que los estudiantes que no se dejan domesticar corren el riesgo de terminar siendo etiquetados (por ejemplo como portadores de TDAH aquellos que no hacen sino hablar con el cuerpo). Y me sigue poniendo muy, muy nervioso leer que el $20 \%$ (o más) de los niños de nuestras escuelas sufren trastornos vinculados con la hiperactividad.....!!. Entonces la pedagogía sensible está llamada a "que los fármacos antidepresivos no sean el remedio de una sociedad ausente. Ni el hastío ni el aburrimiento son sanos para un educador ausente" (ROMERO, p. 29). Tal vez se trate de pensar y mostrar qué enseñamos sobre la corporalidad (y no tanto sobre el cuerpo -la carne que nos molesta y nos preocupa-) en nuestras instituciones educativas. Tal vez se trate de no negar, no discriminar, no repudiar, no esconder, no estigmatizar, no marcar o no monstruar esos cuerpos que a nosotros, como docentes, nos molestan y a menudo ponen a la deriva cualquier intento de transmitir algo desde el paradigma de la tecnología educativa. No quería terminar esta primera parte sin dejar de preguntarme si ¿es posible ofrecer otra mirada al cuerpo? ¿Es posible iluminar la parte oscura de nuestra vida, de nuestros procesos formativos?

\section{PENSAR EL CUERPO MÁS ALLÁ de LA CARNE: SÍMBOLOS Y REGISTROS CORPORALES}

Llegados a este punto es necesario introducir la idea que la fragmentación de las formas de pensar, de concebir el mundo, así como la comprensión general del ser humano, han hecho que históricamente se haya visto como un ser formado por dos estructuras radicalmente separadas: la mente por una parte, y el cuerpo por otra. A la luz de determinadas formas de pensar, esta separación podría parecer obvia, pero vamos a defender que no es así. Si hiciéramos el ejercicio de analizar el concepto "cuerpo" desde un punto de vista gramatical nos daremos cuenta que los sistemas gramaticales no siempre coinciden con las "cosas" a denominar, sinó que cada cultura, cada contexto sociocultural posee formas de denominación específica. Visto 
desde esta perspectiva podemos afirmar que el cuerpo es concebido tal y como se muestra en la tabla siguiente:

Tab. I. Formas semánticas del cuerpo

\begin{tabular}{|c|}
\hline Formas semánticas del cuerpo \\
\hline Entendido en contraposición al alma. Se sustentaría en una \\
antropología dualista. \\
\hline Conceptualizado como la parte física de la persona. Esta parte \\
se limita a lo óseo, lo anatómico, lo orgánico. Se basa en una clara \\
perspectiva materialista. \\
\hline El cuerpo se concibe como sinónimo de persona, de sujeto \\
\hline
\end{tabular}

Adaptado de Planella (2006: 103)

La unidad del ser humano es algo que nos parece fundamental, aunque bien cierto es que a lo largo de los siglos la opción predominante ha sido otra de bien distinta: no unir lo que de natural debería estar separado. A lo largo de los tiempos se han combinado formas de entender el cuerpo que han pasado por ciclos de negatividad y ciclos de positividad. No podemos olvidar el lastre que sustenta la historia del cuerpo, sus distintas visiones y sus posibles interpretaciones y recreaciones imaginarias.

Fig. I. Circularidad de la Historia Corporal

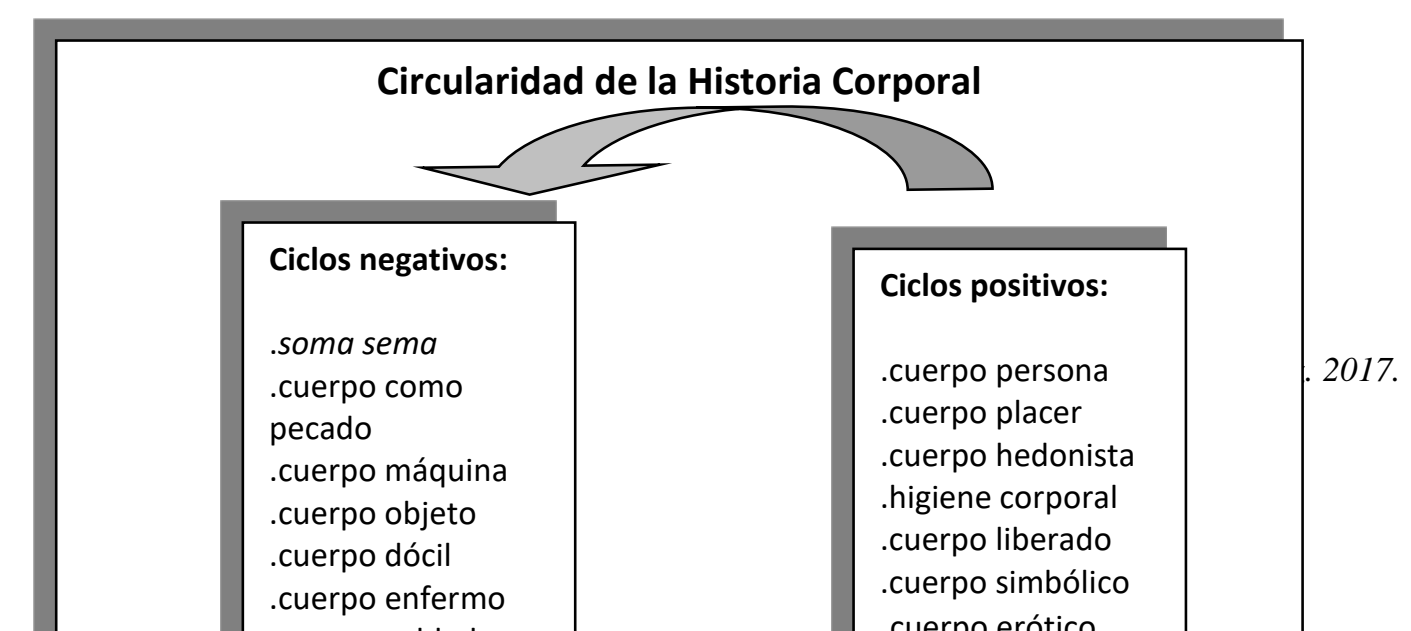


Planella (2006)

Ha sido así que en parte se ha construido un proyecto antropológico que a su vez ha alimentado a una pedagogía que entiende (de forma generalizada) el acto formativo como algo dicotomizado entre el cuerpo y la mente. Y es justamente en esa concepción dividida que se sustenta una parte relevante de la educación escolar. Desde esta perspectiva, es a pesar del cuerpo que se llevan a cabo determinados procesos educativos; el cuerpo es concebido y elegido, en determinadas pedagogías, como el enemigo de todas praxis educativa.

Hablar de educación corporal tiene un especial sentido en el momento y en el contexto en el que nos encontramos. Nos guste o no, lo aceptemos o no, somos "seres primariamente corporales". En nuestras vidas el cuerpo juega un papel fundamental, hasta el punto que podemos afirmar que somos nuestro cuerpo (frente a la clásica concepción materialista que nos habla de la idea que "tenemos un cuerpo"). Tal vez podemos ir más allá y atrevernos a dicer que somos un cuerpo que dice "yo", un cuerpo que toma decisiones, que se posiciona, que se moviliza, que comunica su subjetividad. Ello nos plantea la posibilidad de tener muy presente lo corporal pero traspasando la dimensión puramente anatómica (o por lo menos no quedándonos anquilosados en ella -ya que ese ha sido uno de los principales problemas de determinadas pedagogías-).

\section{Conectar la pedagogía con el cuerpo}


Creo que no será ninguna novedad que afirme que existen diferentes pedagogías y que una de ellas (la que más me atrae personalmente) se interesa por las cuestiones vinculadas con lo sensible y no lo abandona hasta sacarle el máximo jugo posible. Básicamente estamos hablando de una pedagogía del cuerpo físico y una pedagogía del cuerpo simbólico.

La primera (la pedagogía del cuerpo físico) tiene por objeto la higienización de los cuerpos y tiene un especial interés en clasificarlos, ordenarlos, estudiarlos, controlarlos, y si es necesario, castigarlos. Cuando el cuerpo es estudiado, siempre lo es desde el punto de vista biológico. En general se trata de operaciones pedagógicas que se centran en:

-Educar o reeducar dichos cuerpos: a través de ciencias auxiliares de la pedagogía, como por ejemplo la defectología (Rúsia), la pedagogía terapéutica o la pedagogía correctiva. También tendrían cabida las ciencias biomédicas actuales puestas al servicio de la educación (recuperando esa clásica relación entre la Pedagogía y la Medicina, y poniendo en circulación -de nuevo- modelos neo-higienistas.

Borramiento de la diferencia: a través de prácticas radicales como la eutanasia o el aborto cuando hay un diagnóstico fetal de malformaciones genéticas. Estos propiamente no son ejercicios pedagógicos sino biomédicos. También con un cierto aislamiento-separación de los cuerpos que representan de forma radical la diferencia: escuelas de educación especial, aulas especiales, aulas de acogida para alumnos extranjeros, escuelas clasificadas como de especial complejidad social, etc.

A menudo, en muchas instituciones educativas actuales, que despliegan amplios dispositivos para el ejercicio de la educación, podemos encontrar ejemplos claros de la pedagogía del cuerpo físico, una pedagogía que muchas veces se traduce en pequeños actos de microviolencia -casi imperceptibles para la sociedad.

Aquí podríamos encajar algunas imágenes que me vienen in mente:

a) Las filas en el patio para acceder a las aulas (con la finalidad de alinear ordenadamente los cuerpos de los educandos)

b) Los niños uniformados en las escuelas (especialmente en el continente europeo que tiene un sentido distinto al de Latinoamérica)

c) Los actos de expulsión de las aulas de los niños que son "primariamente corporales" (eliminar la presencia de los cuerpos que molestan y relegarlos a espacios escolares periféricos, a no-lugares docentes) 
d) La separación en habitaciones de niños y de niñas en unas colonias escolares (cuando niñas y niños han pedido específicamente dormir juntos)

e) La inexistencia de algo parecido a la educación sexual que incorpore realmente algo del orden de la diversidad sexual

f) Las reglas explícitas o implícitas que incumben al cuerpo en los espacios escolares (levantar la mano para pedir permiso, mantener la boca cerrada en señal de respeto al maestro, parar atención a las palabras del otro -del que habla-)

g) Castigar a una niña de 9 años a la mesa de los pequeños en el comedor escolar

La segunda tipología, la pedagogía del cuerpo simbólico, ha existido desde siempre, pero en muchas ocasiones ha permanecido escondida o sobreviviendo en los márgenes de las instituciones educativas. Es una pedagogía que se refiere a la dimensión existencial, subjetiva y relacional, se trata de la experiencia educativa del cuerpo propio (frente a la idea de un modelo de cuerpo impuesto) y del cuerpo entendido como cultura (y no como biología). Se trata de cuerpos que también en la escuela corpografían (hablan, comunican, escriben, narran a través de los trazos de su piel, etc.). En esta pedagogía podemos ubicar múltiples imágenes que muchas veces hemos visto:

a) El movimiento de los cuerpos en una clase de expresión corporal o de jazz (baile) donde los cuerpos fluyen, se mueven libremente, buscando y rebuscando los espacios, rompiendo los límites;

b) La disposición no regulada de los cuerpos de los escolares en el aula (un aula no entendida ni dispuesta como un espacio lineal y simétrico);

c) Las posiciones formativas que muestran la diversidad de los cuerpos (cuerpos con diversidad funcional, con diversidad sexual, con diversidad cultural) con completa normalidad,

d) La no separación por género en juegos, actividades, etc recreando formas de poder y de construcción binaria de la realidad, etc.

e) La presencia de niños/as, adolescentes TRANS* en nuestras escuelas

e) Permitir la expresión simbólica de los cuerpos en las aulas, en los patios, en los espacios extradocentes de nuestros establecimientos educativos, etc, etc, etc.

Y eso se hace con maestros que sostienen ellos mismos determinadas posiciones basadas en la diferencia, que las ejercen y las encarnan. Lo vinculado con el cuerpo (o la carne) puede 
llegar a ocupar un espacio central de las prácticas y discursos educativos, y esa centralidad puede ser interpretada de formas bien distintas: políticas vinculadas a la liberación corporal o políticas vinculadas al control de dichos cuerpos. Pero es cierto que los cuerpos ya no son (felizmente ya no podrán volver a ser) silencio, grito enmudecido desde los recónditos rincones de la carne (a menudo putrefacta) sino que ahora son voces que hablan y dan cuenta y razón de su estado. Son cuerpos que manifiestan (a través de las distintas formas de la palabra) lo que atraviesa sus vidas, lo que les acontece, sus "experiencias corporales". Se trata de cuerpos empalabrados (VVAA, 2011). Es ahí que se dibuja una pedagogía de lo sensible, que no busca leer los cuerpos como elementos anatómicos, como algo que los cosifica y nos cosifica a todos. No. Esa pedagogía se alinea con la escritura corporal, con la corpografía. Para mí lo corpográfico, la corpografía, no es algo técnico, sino simplemente se trata de la posibilidad que los cuerpos sean leídos desde lo cultural. Y es aquí dónde necesariamente aparece el lenguaje y lo que a través del lenguaje los cuerpos significan, dicen, hablan, comunican, silencian o corpografían. Es así que el cuerpo se muestra, se enseña, y a menudo ese mostrarse y enseñarse no es fiel a la realidad; una realidad multiforme, variada, configurada de distintas identidades que toman forma en las variadas corporalidades que las encarnan.

Me gusta partir de la máxima que nos dice que la formación es formarse (Gadamer), y en ese contexto la forma del cuerpo se encuentra ligada con el proceso autoformativo. El proceso seguiría este camino: la materia primera del sujeto (el cuerpo entendido desde su dimensión física) es modificada, transformada, formada o deformada por parte de los elementos contextuales que participan en ese proceso. Si el sujeto se deja modificar sin más, será objeto de instrucción a través de lo que podemos denominar currículum corporal cerrado. En el currículum corporal cerrado los cuerpos se forman a partir de determinados criterios que podemos organizar como:

- cuerpos silenciosos (no portadores de textualidades);

- cuerpos normalizados (que se ajustan a las medidas / características/ estéticas marcadas por esos contextos);

- cuerpos uniformes (que no pueden ser leídos ni interpretados de formas diferentes);

- cuerpos físicos (que no disponen de una perspectiva simbólica);

- cuerpos obedientes (que se someten a los elementos biopolíticos que marcan las praxis pedagógicas). 
Por contra, hablar de la dimensión simbólica del cuerpo y de su pedagogía es posible porqué cada vez se entiende menos el cuerpo como cuerpo-objeto y más como cuerpo-sujeto. Esa pedagogía simbólica del cuerpo bebe de los movimientos antes citados (Escuela Nueva o pedagogía naturalista), ya que se trata de pedagogías interesadas especialmente en la dimensión simbólica del cuerpo.

\section{CUIDAR EL CUERPO EN LA ESCUELA}

Desde este paradigma de la pedagogía sensible se subvierte la mirada negativa al cuerpo, se invita a acercarse al Otro, a mirarlo, a acariciarlo desde el contacto, a desplegar el sentido del olfato, a recordar los sabores y los olores que configuraron la esencia de nuestras infancias. Se trata de "cuidar el cuerpo".

\section{Pedagogía de la piel}

La piel, a pesar de un gran desconocimiento común, es el órgano más grande del cuerpo humano. En palabras de Gottlieb "La piel es el mayor órgano sensorial del cuerpo, y el sistema táctil el primer sistema sensorial que se hace funcional en la especie humana" (GOTTLIEB, 1971). Nuestra piel ocupa la superficie de $2.000 \mathrm{~cm} 2$ y dispone de un total de 1.800 .000 receptores. Puede llegar a representar el $12 \%$ del peso corporal total. Ello nos lleva a pensar dicho órgano como algo especial, relevante, algo que me permite entrar en contacto con el mundo, que me da informaciones de él y que la da informaciones sobre mi ser. Todo ello llevó a Nikki Giovanni a afirmar que "tocarse fue, sigue siendo y siempre será la verdadera revolución". Cuando hablamos de la piel hablamos de algo muy potente que no podemos olvidar. Pero la piel no se limita a ser nuestro envoltorio, sino que tiene muchas posibilidades de uso funcional. Eso le da inmensas oportunidades de interaccionar con su entorno.

Un ejemplo de la interacción del cuerpo con su entorno es el de Hellen Keller, una niña sorda y ciega de nacimiento que era capaz de identificar todo tipo de sintonías y sonidos a través de las vibraciones que sentía con las plantas de sus pies desnudos. Era su piel que le ponía en contacto con el mundo musical, y se conectaba así con su entorno. Somos seres de tacto y el tacto tiene un campo de posibilidades y experimentaciones casi infinito a través de los poros y extensiones nerviosas que llegan hasta nuestra piel. La piel nos muestra, y en ese mostrarse como algo, nos identifica. 
La piel puede ser usada, en la sociedad y en la escuela en particular, como materia primera de las tecnologías de la alienación. Lo plantea el profesor Mozart Linares al decir que "el negro es constituido como una identidad ambivalente, entre las posibilidades de visibilidad y de invisibilidad" (LINARES, 2011, p. 113). Hacer de la piel territorio de estigma, territorio de "maldad" en lugar de espacio de contacto (poner en juego en el tacto con el otro). Pero lo queramos o no, nos guste o no, la pedagogía sigue dando la espalda a la piel, al tacto a nuestra dimensión "sensible".

¿Porqué la Pedagogía da la espalda a la piel y al tacto?. Las sensaciones y los aprendizajes que obtenemos a través de la experiencia (de lo que me sucede de forma encarnada), provocan placeres, deseos y saberes que pasan, por ejemplo, por sentir como se eriza nuestra piel. ¿Podemos luchar contra ello? ¿O es mejor aprovecharlo para hacer de ese acto sublime -placerdeseo-saber un acto pedagógico?. Tal vez la carta que Franz Kafka (un escritor obsesionado con el cuerpo y sus representaciones) envió a su amigo Oscar Pollack hace casi cien años, pueda ofrecer un poco de luz a lo que procuramos mostrar.

Estoy sentado ante mi hermoso escritorio. No lo conoces ¿Cómo podrías? Se trata, concretamente, de un buen escritorio burgués, bien organizado, pensado para tareas docentes. Tiene en el sitio donde de ordinario se hallan las rodillas del escritor, dos terribles puntas de madera. Y ahora presta atención. Cuando uno está terriblemente sentado, es cuidadoso y escribe algo bueno y burgués, entonces está perfectamente. Pero, ay de ti si te emocionas y mueves el cuerpo aunque solo sea un poco, porque entonces, inevitablemente, se te clavan las maderas puntiagudas en las rodillas y ¡como duele! Te podría enseñar los cardenales. ¿Y qué es lo que eso quiere decir?: "No escribas nada emocionante y no permitas que tu cuerpo se mueva".

Kafka es autor que en muchos de sus textos se ha preocupado por el cuerpo. La carta que envía a su amigo recoge de forma muy parecida la esencia de lo que le sucede al cuerpo en muchas instituciones educativas. El cuerpo del educando, del estudiante, a menudo se convierte en cuerpo que no puede dejar de ser cuerpo-quieto, cuerpo-sin-emociones, cuerpo-sinsensibilidad; el cuerpo que no está quieto es un cuerpo que inquieta al docente. Kafka nos habla de un mueble, de un mueble típicamente burgués pero también típicamente del mueble en el que un estudiante puede pasar muchas horas de su vida. Pero ese escritorio, a pesar de que por fuera pueda ser el mismo que otros, no lo es. Este incorpora un mecanismo físico de control de la sensibilidad, de las pasiones de los sujetos que en él se sientan. Estar sentado, quieto y sin moverse es lo que buscaba el ebanista que construyó el escritorio. Creo que eso forma parte del sueño de algunos docentes que siguen viendo en el cuerpo una verdadera fuente de problemas 
y molestias radicales. Este escritorio simboliza el paradigma platónico y cartesiano, tal vez depurado por la moral victoriana, que ven en la carne una posibilidad de dejar perder las mentes de los estudiantes.

Entre la piel que toca y la piel que recibe, se establece un verdadero diálogo: la piel escucha lo que la mano le dice y le responde. La metáfora de la textualidad corporal juega un rol fundamental en las construcciones sociales del cuerpo, especialmente desde la hermenéutica de la textualidad corporal que nos invita a pensar el cuerpo como un territorio dónde es posible el ejercicio de la propia escritura. De hecho, los cuerpos desde la pedagogía deberían tener ese objetivo: resistirse a la hegemonía de la normalidad, de los cuerpos normales que hablan por los otros cuerpos; resistirse a que esos otros cuerpos sean silenciados, acallados y sometidos.

\section{Pedagogía del perfume}

Oler, reconocer al otro por el perfume que desprende es una forma ancestral de ejercer las relaciones humanas. Lo que sucede es que con la depuración de los cuerpos en la sociedad contemporánea, los olores han sido negados, han sido borrados o bien han sido conceptualizados como algo negativo que debemos repudiar. El cuerpo es un verdadero "agente del sentido" y a través de él marca territorios y fronteras con los otros cuerpos. Pero contra eso es difícil luchar, especialmente en nuestra infancia y a través de las experiencias que atraviesan nuestras vidas en la escuela. ¿Quien no recuerda el perfume de una maestra?... ¿quien no recuerda también los olores de la escuela?; olores y malores olores, siempre presentes (a pesar de todas las acciones por negarlos) porqué el cuerpo (a pesar del trabajo de control) no ha podido controlar y eliminar algo tan vital como el sentido del olfato. En un ejercicio realizado por Miguel Beas (Sevilla) (Esteban, 2013) con estudiantes de la Facultad de Educación aparecieron algunas ideas como las siguientes en relación a sus recuerdos sobre el perfume en la escuela:

Tab. II. Pensamientos sobre el perfume en la escuela

\begin{tabular}{|lc|r|}
\hline \multicolumn{1}{|c|}{ Relato } & $\begin{array}{r}\text { Pensamientos sobre el perfume en la escuela } \\
\text { La vida es olor, perfume agradable o no, pero fragancia. Fragancia en el hogar, } \\
\text { en la calle, en el aula, en el trabajo, en las personas más o menos cercanas. }\end{array}$ \\
\hline \multirow{2}{*}{2} & Relato & $\begin{array}{r}\text { De preescolar me gustaba el olor que apreciaba un poco antes de la hora del } \\
\text { recreo, no sé por qué pero era solo a esa hora cuando me llegaba el olor a bocadillos, } \\
\text { a papel de aluminio, a chorizo, jamón york, atún... }\end{array}$ \\
\hline
\end{tabular}




\begin{tabular}{|c|c|}
\hline Relato & $\begin{array}{l}\text { El sistema educativo también está impregnado de múltiples fragancias que se } \\
\text { acumulan durante el tiempo y que se rescatan del olvido cuando recordamos el pasado } \\
\text { escolar o cuando percibimos algún olor similar que nos transporta en el tiempo a } \\
\text { vivencias y emociones pasadas. }\end{array}$ \\
\hline Relato & $\begin{array}{l}\text { Cuando llegué a primaria nos cambiaron de planta; ya éramos mayores y eso se } \\
\text { notaba en los olores. Había desaparecido el olor a plastilina, a pegamento y a pinturas; } \\
\text { ahora, lo que resaltaba, sobretodo al principio del curso, el olor a libros, a libros nuevos } \\
\text { a estrenar. }\end{array}$ \\
\hline Rel & $\begin{array}{l}\text { Quizás el olor más característico de Primaria es el de esa tiza que chirriaba en } \\
\text { la pizarra y que soltaba un polvo blanco que dejaba un olor que penetraba en nuestras } \\
\text { narices y que a algunos nos hacía asfixiarnos. }\end{array}$ \\
\hline Relato & $\begin{array}{l}\text { En Primaria olía a alegría, a ilusión. Todos estábamos siempre entusiasmados } \\
\text { y animados para realizar cualquier actividad; se respiraba felicidad. }\end{array}$ \\
\hline Relato & $\begin{array}{l}\text { El laboratorio de Física olía a hospital y el de Biología olía a carne, porque } \\
\text { hacíamos prácticas con corazones de cochino, con pulmones y con ojos. El gimnasio } \\
\text { hacía olor a pies, a colchonetas, a maderas pasadas. Los servicios desprendían un hedor } \\
\text { horrible a orina... Prácticamente todos los días en la hora del patio este mal olor se } \\
\text { mezclaba con el tabaco. }\end{array}$ \\
\hline
\end{tabular}

Beas (en Esteban 2013)

Los relatos de las narrativas del cuerpo vinculadas con los olores en la escuela son claros, no pueden ser silenciados ¿Cómo podríamos negar, eliminar o en cierta forma silenciar, los perfumes que se desprenden en los establecimientos educativos? Se trata de un lenguaje libre, a veces molesto (tal y como algunos relatos nos han sugerido) pero al fin y al cabo un lenguaje que nos transmite múltiples saberes y olores sobre el Otro. La educación corporal, la pedagogía sensible, simboliza otra forma, ni antigua ni nueva, de llevar a cabo los procesos que hacen que el ser humano llegue a ser justamente eso. Permite el desarrollo de la subjetividad de manera amplia, sin las sombras que determinadas morales, políticas, pedagogías proyectan en la persona. Nos permite darnos cuenta que más allá de los reglamentos escolares, los modelos de ejercer la docencia, los currículums o las praxis educativas, el sujeto -como cuerpo encarnadotiene la necesidad de proyectarse, de ejercer como ser de proyecto, y esa proyección tiene unas posibilidades increíbles a partir de la vivencia de su corporalidad.

\section{CONCLUSIONES: CUERPOS QUE HABLAN EN LOS CONTEXTOS EDUCATIVOS}


A través de dispositivos pedagógicos se materializa la "desaparición ritualizada del cuerpo", que incluye los gestos, las posturas, las distancias entre sujetos, los deseos y su anunciación, etc. A través de variados mecanismos se ordenan estas maneras de hacer, y es entonces que no pueden tener cabida ni los sentidos, en general ni el tacto en particular. Podríamos hablar de maestros de lo sensible y maestros de la intelectualidad. Esta pedagogía (la de lo Sensible) intenta proponer un modelo corporal que pueda superar perspectivas históricas, en parte, todavía vigentes, que categorizan el cuerpo desde una óptica negativa. Más allá de las hermenéuticas que entienden a los cuerpos como elementos a disolver, controlar, eliminar o subyugar, nos situamos en una lectura del cuerpo como espacio de posibilidad para la inscripción del sujeto en lo social.

Aunque rechace la negatividad corporal, tampoco quiero posicionarme en la perspectiva del dualismo posmoderno que busca una descorporeización de los sujetos en pro de su virtualización. Buscamos una pedagogía situada en lo que Touraine define como la "Escuela del Sujeto", donde el cuerpo no es un cuerpo que tenemos, sino que el cuerpo somos nosotros mismos. En definitiva, propongo una pedagogía que busca romper con las estructuras binarias y con la construcción de un modelo dualista en el cual el hombre es concebido como cuerpo y alma. La pedagogía de la corporeidad se encuentra enmarcada en el ciclo de positivdad corporal, en lugar de hacerlo en el ciclo de negatividad. El cuerpo no es aquel enemigo que nos priva de alcanzar el conocimiento, sino que podemos alcanzar el conocimiento a través y desde nuestra vivencia de la corporeidad.

Voy a terminar leyendo unos breves textos:

A) "El cuerpo: así es como lo hemos inventado ¿quién más en el mundo lo conoce?". Jean-Luc Nancy, Corpus, 2003, pág. 8.

B) Actualmente me gustaría encontrar simplemente el tono de aquel profesor de literatura que me sacó de entre los malos estudiantes. Quizá porque en vez de censurar, daba confianza; quizá por su paciencia de pescador de cana y su acogedora bondad. Hay dos clases de maestros, como es sabido: los que a base de darte la impresion de que eres inteligente, capaz y esforzado terminan por convertirte en tal, y los que te cortan las alas. Evidentemente él estaba entre los primeros. Se convirtió en un amigo y más que sus cualidades pedagogicas lo que aprecio ahora es su capacidad de acuarelista y de poeta (al estilo de Prevert). Lo que me ha marcado más 
profundamente no ha sido tanto su saber cuanto su inmenso amor por el hombre y su humildad [...] Con el se comprendía que la literatura no se aprende sino que se vive: es un arte de vivir. Michel Barlow, Journal d'un professeur debutant. Paris: Centurion, 1969, p. 30.

\section{BIBLIOGRAFÍA}

AGAMBEN, Giorgio. Infancia e historia: ensayo sobre la destrucción de la experiencia. Buenos Aires: Adriana Hidalgo, 2007.

ANDRIEU, Bernard. Le corps dispersé: une histoire du corps au XXè siècle. París: L'Harmattan, 1993.

ASSMANN, Huco. Placer y ternura en educación: hacia una Sociedad aprendiente. Madrid: Narcea, 2002.

BENITO, Pilar. Baruch de Spinoza: una nueva ética para la liberación humana. Madrid: Biblioteca Nueva, 2015.

BENJAMIN, Walter. Sobre arte, técnica, linguagem e política. Lisboa: Relógio d'Água, 2002.

CUPA, Dominique. Une topologie de la sensualité: le moi-peau. Revue française de psychosomatique, París: PUF, v. 29, p. 83-100, 2006.

DAMASIO, Antonio. El error de Descartes: la emoción, la razón y el cerebro humano. Madrid: editorial Crítica, 2006.

ESQUIROL, Josep Ma. La resistencia íntima: ensayo de una filosofía de la proximidad. Barcelona: Acantilado, 2015.

ESTEBAN, Joaquín (ed.). Marcas del cuerpo en educación: imaginarios simbólicos y materiales. Valladolid: Universidad Europea Miguel de Cervantes, 2013.

FOUCAULT, Michel. L'archéologie du savoir. París: Gallimard, 1969.

GAMELLI, Indro. Pedagogia del corpo. Roma: Meltemi, 2002.

GALLO, Silvio. Deleuze \& a Educaçâo. Bello Horizonte: Autêntica, 2003.

GOTTLIEB, G. Ontogenesis of Sensory Function in Birds and Mammals, in E. TOBACH, E.; L. R. ARONSON, L.R.; SHAW, E. (comps.) The Biopsychology of Development. Nueva York: Academic Press, 1971.

LARROSA, Jorge. Nietzsche \& a Educaçâo. Bello Horizonte: Autêntica, 2007. 
LINARES, Linares. Educaçâo e diferença: narrativas legitimadoras e sujetitos étnicos no sul do Brasil, in B. HILlESHEIM, B.; GUSTACK, F.; VIEGAS, M.F.(Org.) Pesquisa, Políticas e Formaçâo de professores. Distintos olhares. Santa Cruz do Sul: Edunisc, 2011.

PLANELLA, Jordi. Cuerpo, cultura y educación. Bilbao: Desclée de Brouwer, 2006.

PLANELLA, Jordi; PIÉ, Asun (Coord.). Politicas prácticas y pedagogías TRANS. Barcelona: Ediuoc, 2015.

ROMERO, Gonzalo. La identidad de la escuela educadora, in ROMERO, G; CABALLERO, A. (eds.) La crisis de la escuela educadora. Barcelona: Laertes, 2009.

SERRES, Michel. Os cinco sentidos: filosofia dos corpos misturados. Rio de Janeiro: Bertrand Brasil, 2011.

UBIETO, José Ramón. TDHA Hablar con el cuerpo. Barcelona: Ediuoc, 2014.

VEIGA-NETO, Alfredo. Foucault \& a Educaçâo. Bello Horizonte: Autêntica, 2003.

VVAA. Emparaular el món. El pensament antropològic de Lluís Duch. Barcelona: Fragmenta Editorial, 2011. 